\title{
TRAIL enhances paracetamol-induced liver sinusoidal endothelial cell death in a Bim- and Bid-dependent manner
}

\author{
A Badmann ${ }^{1}$, S Langsch ${ }^{1}$, A Keogh ${ }^{2}$, T Brunner ${ }^{3}$, T Kaufmann ${ }^{4}$ and N Corazza*,1
}

Paracetamol (acetaminophen, APAP) is a universally used analgesic and antipyretic agent. Considered safe at therapeutic doses, overdoses cause acute liver damage characterized by centrilobular hepatic necrosis. One of the major clinical problems of paracetamol-induced liver disease is the development of hemorrhagic alterations. Although hepatocytes represent the main target of the cytotoxic effect of paracetamol overdose, perturbations within the endothelium involving morphological changes of liver sinusoidal endothelial cells (LSECs) have also been described in paracetamol-induced liver disease. Recently, we have shown that paracetamol-induced liver damage is synergistically enhanced by the TRAIL signaling pathway. As LSECs are constantly exposed to activated immune cells expressing death ligands, including TRAIL, we investigated the effect of TRAIL on paracetamol-induced LSEC death. We here demonstrate for the first time that TRAIL strongly enhances paracetamol-mediated LSEC death with typical features of apoptosis. Inhibition of caspases using specific inhibitors resulted in a strong reduction of cell death. TRAIL appears to enhance paracetamol-induced LSEC death via the activation of the pro-apoptotic BH3-only proteins Bid and Bim, which initiate the mitochondrial apoptotic pathway. Taken together this study shows that the liver endothelial layer, mainly LSECs, represent a direct target of the cytotoxic effect of paracetamol and that activation of TRAIL receptor synergistically enhances paracetamol-induced LSEC death via the mitochondrial apoptotic pathway. TRAIL-mediated acceleration of paracetamol-induced cell death may thus contribute to the pathogenesis of paracetamol-induced liver damage. Cell Death and Disease (2012) 3, e447; doi:10.1038/cddis.2012.185; published online 20 December 2012

Subject Category: Experimental Medicine

Paracetamol (acetaminophen, APAP) is a widely used analgesic and antipyretic drug. ${ }^{1}$ Although safe at therapeutic doses, overdose causes massive liver damage characterized by hemorrhagic centrilobular necrosis. ${ }^{2}$ Although substantial efforts have been made to delineate the mechanisms of paracetamol-induced liver destruction, the biochemical events and their cellular targets leading to the disease are still not completely understood.

Hepatocytes represent the most prominent target of paracetamol-induced toxicity. Paracetamol is metabolized within hepatocytes via the cytochrome P450 enzyme system into the toxic compound $\mathrm{N}$-acetyl-p-benzoquinone imine (NAPQI), which at therapeutic doses is detoxified by glutathione. However, overdoses lead to hepatic glutathione depletion and NAPQI to cause mitochondrial dysfunctions resulting in cell death. ${ }^{3,4}$

Whereas paracetamol overdose seems to lead to hepatocellular death displaying necrotic features ${ }^{3,5}$ mitochondrial events linked to apoptosis have also been implicated., ${ }^{6,7}$
These include the proteolytic processing of the pro-apoptotic $\mathrm{Bcl}-2$ family member Bid into truncated tBid, the translocation of tBid and Bax to mitochondria and the release of cytochrome $c$ from mitochondria into the cytosol. ${ }^{6,7}$ We have recently shown that paracetamol-induced hepatocyte death is synergistically enhanced by TNF-related apoptosis-inducing ligand (TRAIL). Furthermore, we demonstrated that the activation of the pro-apoptotic $\mathrm{BH}$-only protein Bim via the stress kinase c-Jun N-terminal kinase (JNK) regulates paracetamolinduced hepatocellular death. ${ }^{8}$

Whereas one of the major and common clinical problems of paracetamol-induced liver disease is the development of hemorrhagic alterations suggesting damage of the endothelial layer, few efforts have been put into the understanding of the fate of liver sinusoidal endothelial cells (LSECs) after paracetamol overdoses. It has been demonstrated that centrilobular microvascular congestion, thought to be caused by the collapse of the sinusoidal wall and the extra vasation of blood into the space of Disse, represents an important

\footnotetext{
${ }^{1}$ Division of Immunopathology, Institute of Pathology, University of Bern, Bern, Switzerland; ${ }^{2}$ Visceral and Transplantation Surgery, University Hospital, University of Bern, Bern, Switzerland; ${ }^{3}$ Biochemical Pharmacology, Department of Biology, University of Konstanz, Konstanz, Germany and ${ }^{4}$ Institute of Pharmacology, University of Bern, Bern, Switzerland

${ }^{*}$ Corresponding author: N Corazza, Institute of Pathology, University of Bern, Murtenstrasse 31, Bern, CH-3010, Switzerland. Tel: +41 316323208 ; Fax: +4131 38187 64; E-mail: nadia.corazza@ pathology.unibe.ch

Keywords: liver sinusoidal endothelial cells (LSEC); paracetamol; TRAIL; Bcl-2 homologs; apoptosis

Abbreviations: acLDL, acetylated low-density lipoprotein; APAP, acetaminophen, paracetamol; CHOP, C/EBP homologous protein; ERK, extracellular-signal regulated kinase; ER, endoplasmatic reticulum; FITC, fluorescein isothiocyanate; FLIP, FLICE-like inhibitory protein; H\&E, hematoxylin-eosin; IFN- $\gamma$, interferon gamma; LSECs, liver sinusoidal endothelial cells; JNK, c-Jun N-terminal kinase; NKT, natural-killer T-cells; NK, natural killer cell; ROS, reactive oxygen species; TRAIL, TNFrelated apoptosis-inducing ligand; PFA, paraformaldehyde; PI, propidium iodide; PBS, phosphate-buffered saline; VEGF-a, vascular endothelial growth factor-a Received 12.9.12; revised 6.11.12; accepted 9.11.12; Edited by G Melino
} 
attribute of paracetamol-induced liver disease. ${ }^{9-12}$ These observations suggest that during the onset of paracetamolinduced liver damage the blood vessels are injured, and the cells forming the barrier between the blood stream and hepatocytes represent an additional and potentially important target of paracetamol-induced liver damage. ${ }^{13}$ Damage of the hepatic vasculature has been recognized as an early hallmark of paracetamol-induced liver damage. As early as $2 \mathrm{~h}$ after paracetamol challenge perturbations within the endothelium, involving swelling of LSECs, gap formation and the coalescence of fenestrae have been observed, indicating that LSECs are able to metabolize paracetamol and are susceptible to its toxic metabolite. ${ }^{9}$ These changes in morphology of the endothelium facilitate the subsequent infiltration of blood cells and their accumulation in the space of Disse, and most probably represent an early event in the pathogenesis of paracetamol-induced liver injury.

As LSECs are constantly exposed to activated immune cells expressing death ligands and we previously demonstrated that TRAIL synergizes with paracetamol in liver toxicity, ${ }^{8}$ we here investigated the effects of TRAIL and paracetamol on LSEC death. We demonstrate for the first time that TRAIL synergizes with paracetamol to induce cell death in different endothelial cell lines as well as in primary murine and human LSECs. We further demonstrate that the $\mathrm{BH} 3-$ only proteins Bim and Bid have an essential role in the synergistic LSEC death induced by paracetamol and TRAIL. Taken together, these data indicate that (1) LSECs represent a direct target of the cytotoxic effect of paracetamol and TRAIL, and (2) similar cytotoxic molecular mechanisms exist in LSECs as in hepatocytes. Both points represent an important and additional new piece of information to the further understanding of liver pathology in response to paracetamol overdoses.

\section{Results}

Paracetamol-induced endothelial cell death is synergistically enhanced by TRAIL. We have previously shown that TRAIL synergistically enhances paracetamolinduced hepatocyte death. ${ }^{8}$ One of the major clinical problems of paracetamol-induced liver disease is the development of hemorrhagic alterations as a consequence of endothelial layer damage. ${ }^{10,12}$ We therefore investigated the effect of paracetamol in combination with TRAIL on endothelial cell death. The human endothelial cell line skHep-1 and the immortalized human umbilical vein endothelial cell line EA.hy $926^{14}$ were stimulated with sublethal doses of TRAIL, increasing concentrations of paracetamol or the combination thereof, and cell death was monitored by MTT assay (Figure 1a) and phosphatidylserine externalization (Figure 1b). Both endothelial cell lines were sensitive to the cytotoxic effect of paracetamol alone, indicating that endothelial cells express enzymes required for drug metabolism. The ability of LSECs to metabolize different drugs was already demonstrated in previous publications. ${ }^{13,15-17}$ For instance, DelLeve et al. ${ }^{13}$ showed that sinusoidal endothelial cells are targets for acetaminophen toxicity. This result was also corroborated by the detection of cytochrome
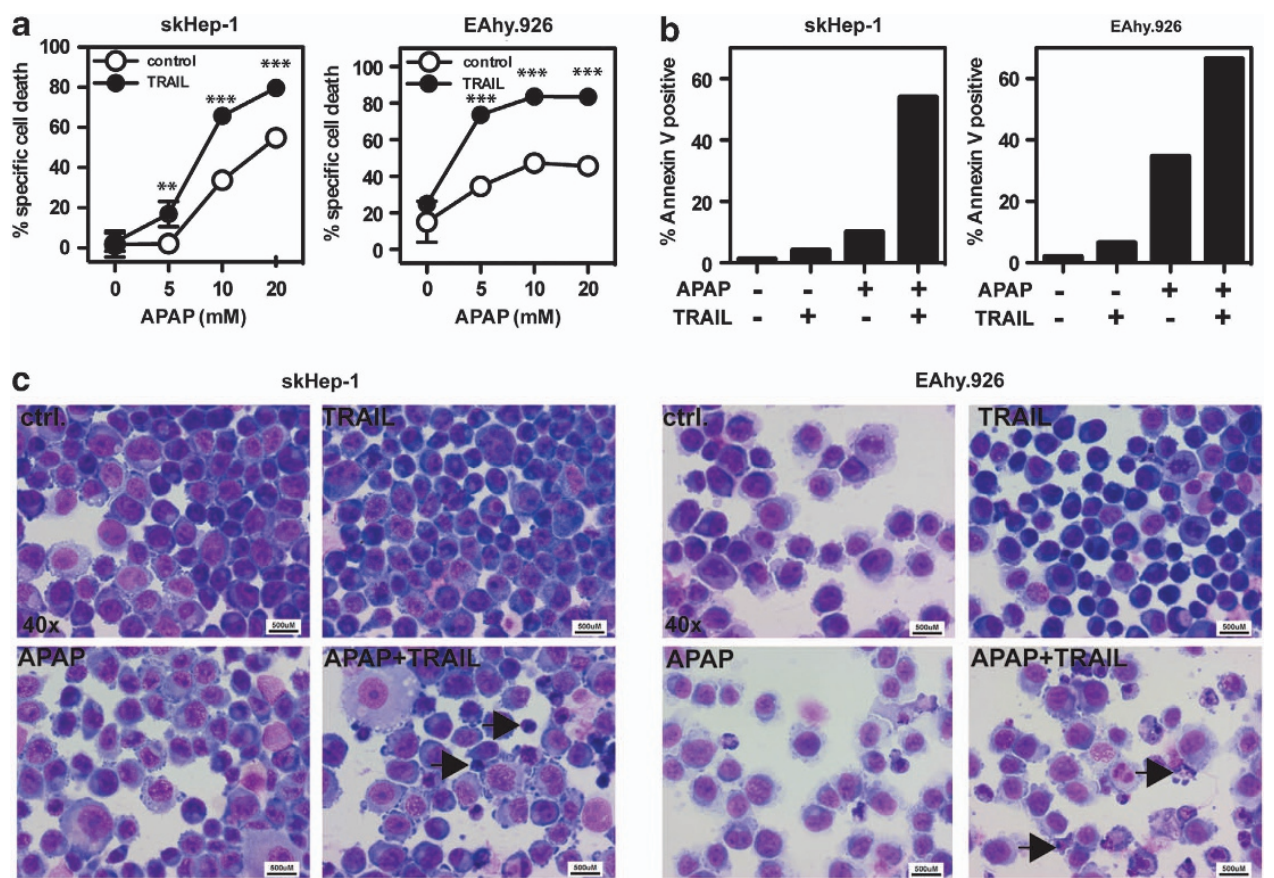

Figure 1 TRAIL synergizes with paracetamol in inducing endothelial cell death. The human cell lines skHep-1 or EA.hy926 were stimulated with TRAIL and paracetamol and cell death was assessed by MTT assay (a) or by Annexin V-FITC staining $16 \mathrm{~h}$ after stimulation (b). Cells were treated with media or increasing concentrations of paracetamol or with $10 \mathrm{mM}$ paracetamol, $30 \mathrm{ng} / \mathrm{ml}$ respectively $3 \mathrm{ng} / \mathrm{ml}$ TRAlL or the combination thereof and harvested and cytospin was performed at $600 \mathrm{rpm}$ for $2 \mathrm{~min}$. Cells were microscopically visualized after hematoxylin and eosin staining (c). Mean values \pm S.D. triplicates are shown for MTT assay, which were repeated four times, yielding similar results. A typical experiment out of three is shown for Annexin V staining. ${ }^{* * *} P<0.001,{ }^{* \star} P<0.01$ versus paracetamol alone treated cells 
P450 mRNA expression (CYP2E1) in both cell lines (Supplementary Figure 1). Interestingly, the combination of TRAIL with increasing concentrations of paracetamol leads to a significant increase of endothelial cell death (Figures 1a and $b$ ). This synergistic induction of cell death was confirmed by increased numbers of cells with typical apoptotic morphology, that is, condensed cytoplasm and nuclei, within $6 \mathrm{~h}$ after treatment with TRAIL and paracetamol (Figure 1c).

Caspase activation is crucially involved in paracetamol plus TRAIL-mediated endothelial cell death. Whereas paracetamol overdose seems to lead to a necrotic type of cell death in hepatocytes, apoptotic events have also been observed. We therefore investigated the contribution of effector caspases in TRAIL- and paracetamol-induced endothelial cell death. Neither paracetamol nor TRAIL alone led to the activation of caspases, as detected by western blot (Figure 2a) or by DEVDase assay (Figure 2b). However, combined treatment of cells with paracetamol and TRAIL leads to the activation of the effector caspase 3 , as demonstrated by proteolytic caspase 3 processing and by the DEVDase assay. The contribution of caspases in paracetamol plus TRAIL-induced endothelial cell death was further supported by the analysis of endothelial cell death using cell-permeable Hoechst 33342 and propidium iodide (PI) (Figure 2c) and MTT assay (Figure 2d). Using both assays, endothelial cell death induced by paracetamol and TRAIL was efficiently attenuated by the pan-caspase inhibitor Z-VAD-fmk.

Critical role for Bim and Bid in the synergistic induction of endothelial cell death by TRAIL and paracetamol. We previously demonstrated that Bim represents an important player in paracetamol-induced hepatocyte death. ${ }^{8}$ Similarly, it had been demonstrated in hepatocytes that paracetamol induces the proteolytic activation of $\mathrm{Bid}^{7}$ We therefore analyzed whether the pro-apoptotic $\mathrm{Bcl}-2$ homologs Bim and Bid represent important initiators of mitochondrial alterations upon paracetamol plus TRAIL treatment. Western blot analysis revealed that treatment of skHep-1 and EA.hy926 cells with paracetamol resulted in a strong induction of Bim expression (Figure $3 \mathrm{a}$ ). In contrast, no increase in Bim levels was observed in both cell lines after treatment with TRAIL alone. Combined treatment of cells with TRAIL and paracetamol did not further increase the expression of Bim. Instead, no Bid processing was detectable upon stimulation with paracetamol or TRAIL alone. Only the combined treatment with paracetamol and TRAIL lead to the processing of Bid into its active tBid form (p15) in both cell lines.

To define whether the increase in Bim protein levels is a consequence of protein stabilization or of a transcriptional induction of the bim gene, we analyzed bim-mRNA levels. Sub-lethal doses of TRAIL did not affect bim-mRNA expression in both cell lines. In contrast, paracetamol strongly promoted bim-mRNA expression. No synergy between paracetamol and TRAIL in promoting bim-mRNA expression was detected (Figure $3 b$ ).

To define the relative contribution of Bid and $\mathrm{Bim}$ in paracetamol plus TRAIL induced endothelial cell death, the expression of these pro-apoptotic Bcl-2 homologs was downregulated by RNA interference, as depicted in Supplementary Figure 2. Cell death in response to paracetamol with or without TRAIL was quantified by measuring AnnexinV binding (Figure 3c). In skHep-1 cells downregulation of Bim or Bid alone resulted only in minimal reduction of endothelial cell death after administration of paracetamol plus TRAIL. However, combined knockdown of Bid and Bim efficiently reduced cell death as demonstrated by the reduction in AnnexinV positivity. Interestingly, in EA.hy926 cell death was already significantly reduced upon knockdown of either Bim or Bid, most probably due to a more efficient knockdown of Bid and Bim compared to skHep-1 (Supplementary Figure 2). The activation and role of Bim and Bid in paracetamol plus TRAIL-induced death suggests an activation of the mitochondrial apoptotic pathway. We therefore analyzed the release of cytochrome $c$ from the mitochondrial inter-membrane space (M) into the cytosol by western blot. Upon stimulation with paracetamol plus TRAIL, release of cytochrome $c$ was detected in both cell lines as illustrated in Figure 3d.

Paracetamol-induced Bim expression is JNK dependent. JNK activity has been shown to be involved in paracetamolinduced liver cell death. ${ }^{18,19}$ Moreover, we previously demonstrated that JNK is implicated in the transcriptional control of Bim expression after paracetamol treatment of hepatocytes. ${ }^{8}$ We therefore investigated whether JNK activation participates in paracetamol plus TRAILmediated endothelial cell death. Inhibition of JNK activity with JNK inhibitor $\mathrm{V}$ decreased the paracetamol-induced bim-mRNA expression in a dose-dependent manner in both cell lines (Figure 4a). To define whether inhibition of bim expression influences the sensitivity of endothelial cells to paracetamol plus TRAIL treatment, we treated cells for 30 min with JNK inhibitor $\mathrm{V}$ prior to adding paracetamol with or without TRAIL. As shown in Figure 4b, JNK inhibition resulted in a significant reduction of caspase activation as detected by DEVDase activity. The reduction of DEVDase activity correlated with the reduced Bim protein levels after JNK inhibitor $\mathrm{V}$ treatment as revealed by western blot (Figure 4c).

Paracetamol plus TRAIL sensitizes primary murine and human LSEC death in a Bim- and caspase-dependent manner. Our in vitro results with both human endothelial cell lines strongly indicate that TRAIL synergizes with paraceta$\mathrm{mol}$ in killing endothelial cells. To confirm that these findings in cell lines are relevant for primary LSECs, we investigated the effect of paracetamol plus TRAIL on ex vivo cultured primary murine and human LSECs. Analogous to skHep-1 and EA.hy926, neither paracetamol nor TRAIL alone induced significant cell death in murine or human LSECs as visualized by Hoechst 33342 and PI staining (Figure 5a). In contrast, both murine and human LSECs displayed synergistic cell death induction upon treatment with paracetamol plus TRAIL. Similarly to skHep-1 and EA.hy926, this synergistic effect was caspase-dependent as demonstrated by reduced PI positivity in the presence of the broad caspase inhibitor Z-VAD-fmk (Figure 5a) and DEVDase activity in 
a
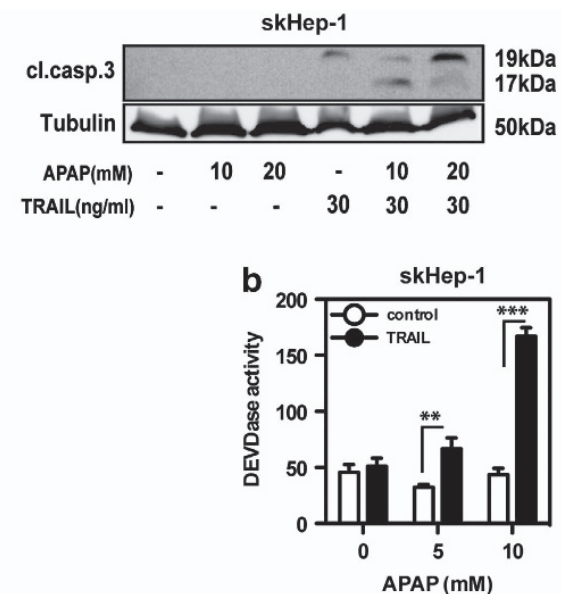
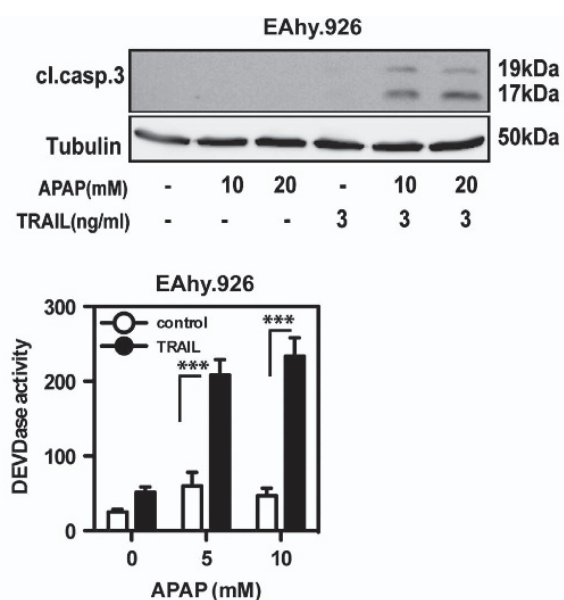
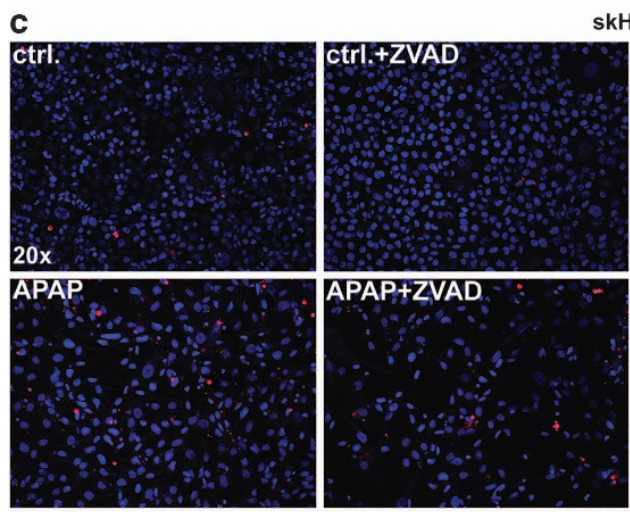

skHep-1
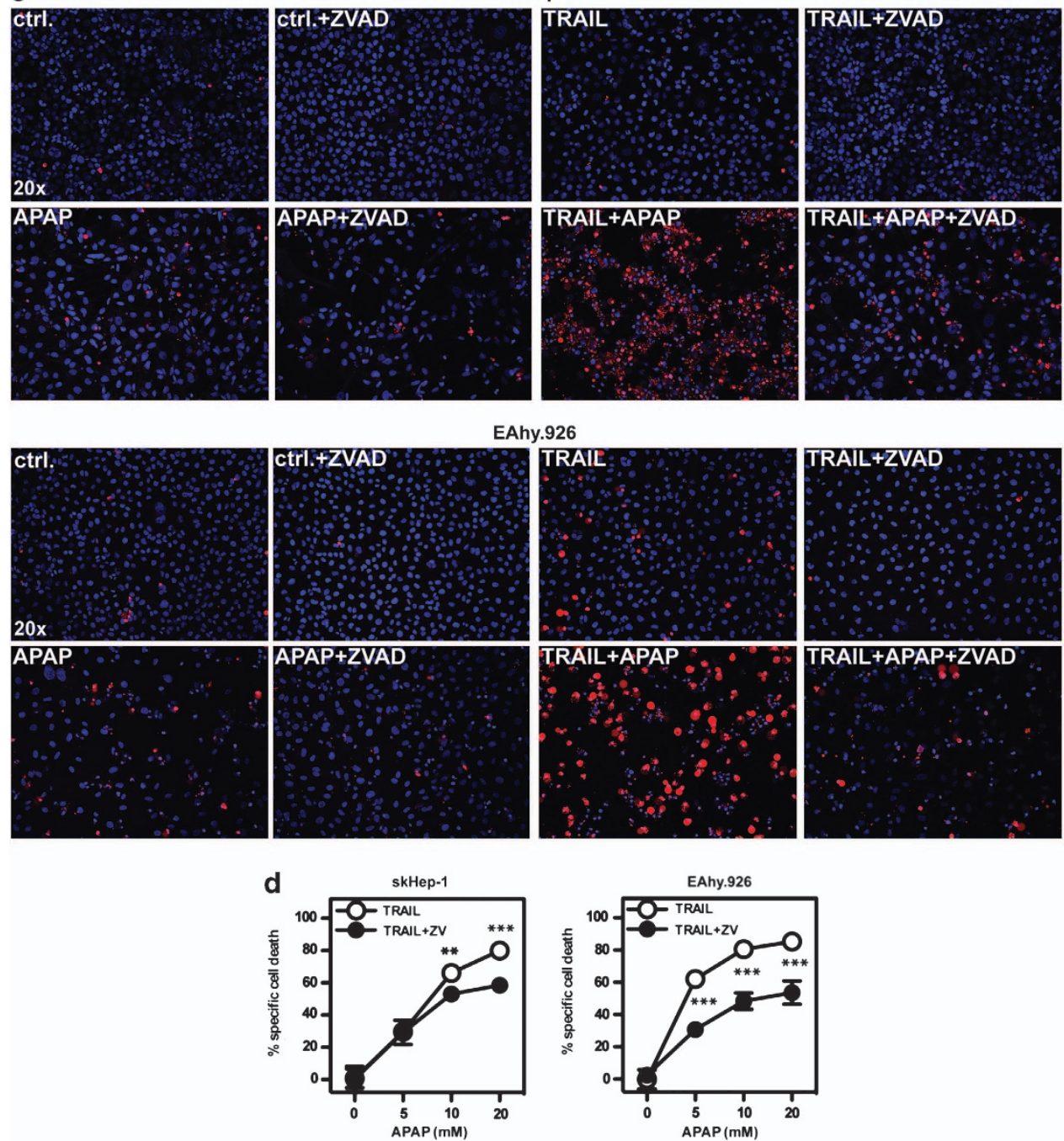

Figure 2 Caspases are crucially involved in paracetamol plus TRAIL mediated endothelial cell death. skHep-1 or EA.hy926 cells were treated with paracetamol (10 or $20 \mathrm{mM}$ ), TRAlL ( $30 \mathrm{ng} / \mathrm{ml}$; respectively $3 \mathrm{ng} / \mathrm{ml}$ ) or both for $6 \mathrm{~h}$, and the protein level of cleaved caspase 3 was analyzed by western blot (a). Tubulin was used to normalize protein loadings. Cell death was assessed by DEVD cleavage assay $7 \mathrm{~h}$ after stimulation (b). Cell death was assed by microscopy after Hoechst 33342 and PI staining (c), or by MTT assay (d). skHep-1 or EA.hy926 cells were pretreated ( $30 \mathrm{~min}$ ) with $10 \mu \mathrm{M}$ caspase inhibitor (ZVAD, ZV) and stimulated with increasing concentrations of paracetamol, 30 , respectively $3 \mathrm{ng} / \mathrm{ml}$ TRAIL, or both for $16 \mathrm{~h}$. Mean values \pm S.D. triplicates are shown for MTT and DEVDase assays. A typical experiment out of five is shown for cleaved caspases 3 . Representative pictures are shown for microscopic analysis. ${ }^{* \star *} P<0.001,{ }^{* \star} P<0.01$ versus paracetamol or paracetamol and TRAlL stimulation 
a
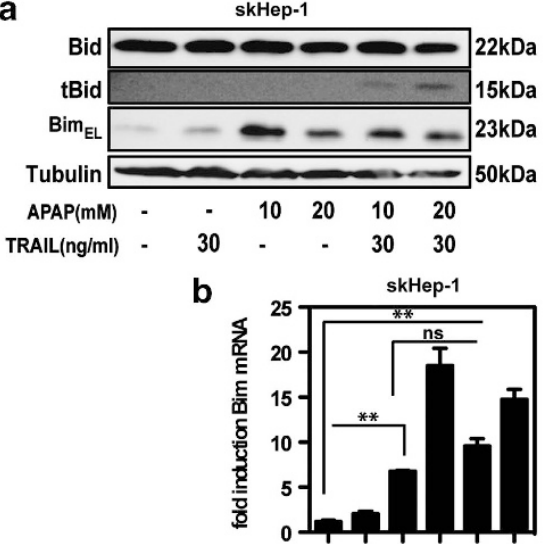

APAP(mM) - . 10201020 TRAIL(ng/ml) - $30 \quad-\quad 3030$

C

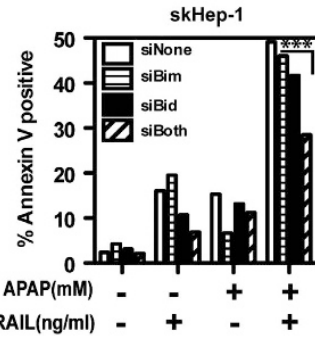

d

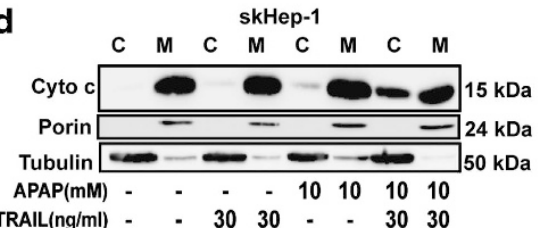

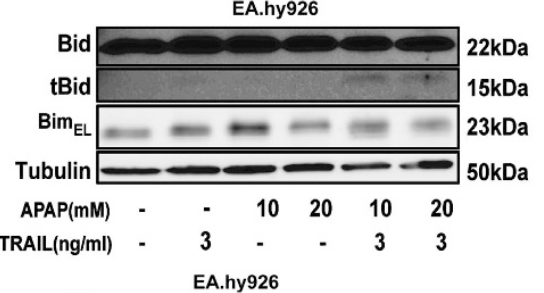

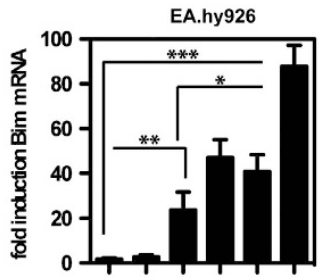

$\operatorname{APAP}(\mathrm{mM})$ - $\quad-10201020$

TRAIL(ng/ml) - $30 \quad-\quad 3030$
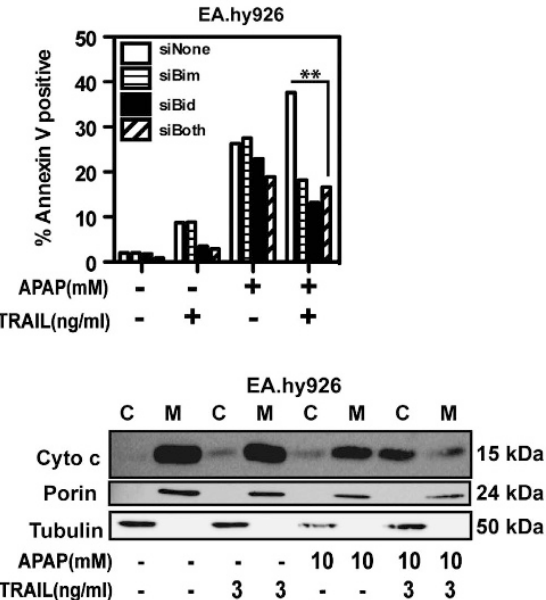

Figure 3 Bim and Bid are crucially involved in the synergistic induction of endothelial cell death by paracetamol plus TRAIL. skHep-1 or EA.hy926 cells were treated for $6 \mathrm{~h}$ with 10 or $20 \mathrm{mM}$ paracetamol, and $30 \mathrm{ng} / \mathrm{ml}$, respectively, $3 \mathrm{ng} / \mathrm{ml}$ TRAlL, or the combination thereof, and Bid, Bim and tubulin as loading control were detected by western blot (a). bim-mRNA expression was measured by quantitative RT-PCR in both cell lines. GAPDH was used to normalize bim-expression levels (b). skHep-1 or EA.hy926 cells were transfected with control (siNone), Bim- or Bid-specific siRNA or the combination of both. Apoptosis sensitivity to paracetamol (10 mM), TRAIL (30, respectively $3 \mathrm{ng} / \mathrm{ml}$ ) or both was analyzed by Annexin V staining after $16 \mathrm{~h}(\mathrm{c})$. Cytoplasmic $(\mathrm{C})$ and mitochondrial fractions $(\mathrm{M})$ were isolated. Cytochrome $c($ Cyto $\mathrm{c})$, porin and, for comparison, twere analyzed in the different fractions by western blot (d). Mean values \pm S.D. triplicates are shown for quantitative RT-PCR. A typical experiment out of five is shown for western blot analysis. bim-mRNA expression, siRNA downregulation as well as cytochrome $c$ western blot were repeated three times yielding similar results. ${ }^{*} P<0.05,{ }^{* \star} P<0.005$, ${ }^{* \star *} P<0.001$

murine LSECs after treatment with paracetamol plus TRAIL Figure 5d.

In human as well as murine LSECs, paracetamol induced expression of Bim both at the mRNA and at the protein level (Figures $5 c$, b and e). To further confirm the importance of Bim and Bid in paracetamol plus TRAIL-mediated cell death, we isolated LSECs from $\mathrm{Bim}^{-/-}$and $\mathrm{Bid}^{-/-}$mice. Figure 6 shows that $\mathrm{Bim}^{-1-}$ as well as $\mathrm{Bid}^{-1-}$ LSECs display attenuated induction of cell death after paracetamol plus TRAIL stimulation compared to wild-type LSECs. Taken together, these findings indicated that LSECs represent a direct target of the synergistic cytotoxic effect of paracetamol plus TRAIL, and that the mitochondrial effector molecules Bim and Bid have an essential role. These results were also confirmed in vivo. Sixty minutes after administration of an overdose of paracetamol, wild-type and $\mathrm{Bim}^{-1-}$ mice were injected with ovalbumin-Texas Red to specifically stain endothelial cells and were sacrificed $30 \mathrm{~min}$ later. Compared to liver sections of PBS-treated wild-type animals, LSEC staining was absent in the affected regions of livers from paracetamol-treated wild-type mice (Figure 7). In contrast, paracetamol treatment of $\mathrm{Bim}^{-1-}$ mice only minimally affected the endothelial structure as compared to wild-type mice, supporting the results obtained from ex vivo cultured LSECs and indicating that Bim also has a central role in paracetamol-induced LSEC death in vivo.

\section{Discussion}

Although hepatocytes are the main target of the toxic effect of paracetamol, several reports indicate that the hepatic vasculature is also injured during paracetamol-induced liver damage. ${ }^{9,10,13}$ Hemorrhagic alteration as a consequence of endothelial layer damage is thus likely a major problem of 
b

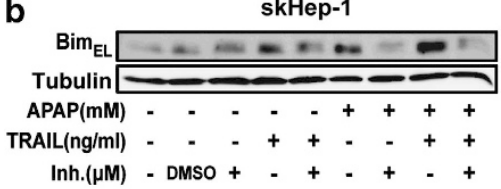

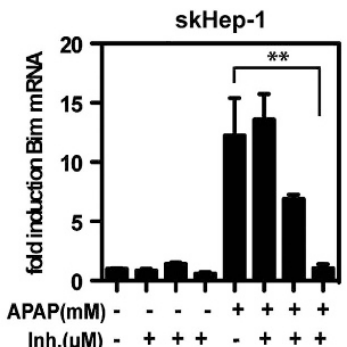
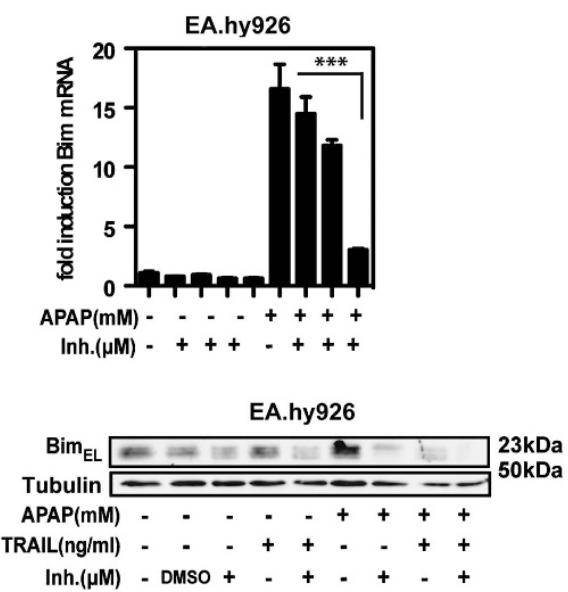

C

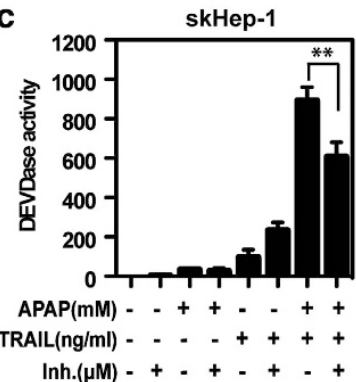

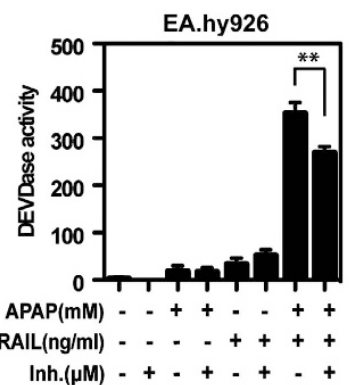

Figure 4 Paracetamol induced Bim expression is JNK-dependent. skHep-1 or EA.hy926 cells were pretreated (60 min) with increasing concentrations of the JNK inhibitor V $(1,3$ and $10 \mu \mathrm{M})$ and stimulated with $10 \mathrm{mM}$ paracetamol for $6 \mathrm{~h}$. bim-mRNA expression was measured by quantitative RT-PCR. GAPDH was used to normalize bimexpression levels (a). skHep-1 and EA.hy926 cells were treated as described above and Bim protein expression was analyzed by western blot. Tubulin was used to normalize protein loadings (b). After pretreatment with $3 \mu \mathrm{M}$ JNK inhibitor V, cells were stimulated with $10 \mathrm{mM}$ paracetamol and $30 \mathrm{ng} / \mathrm{ml}$, respectively $3 \mathrm{ng} / \mathrm{ml}$ TRAlL, or the combination thereof for $6 \mathrm{~h}$ and DEVD cleavage was measured (c). Mean values \pm S.D. triplicates are shown for quantitative RT-PCR and DEVDase assay. A typical experiment out of three is shown for western blot analysis. ${ }^{* \star} P<0.01$ versus paracetamol treatment, ${ }^{* \star} P<0.001$ versus paracetamol treatment

paracetamol-induced liver disease. Perturbations of the endothelium involves swelling of LSECs, gap formation and the coalescence of fenestrae, facilitating the subsequent leakage of red blood cells through these gaps. ${ }^{9,10,12,13,20}$ Our experiments indicate that paracetamol not only induces morphological changes in LSECs but also directly triggers cytotoxic effector mechanisms.

LSECs exhibited only minor sensitivity to the cytotoxic effect of paracetamol alone, whereas addition of TRAIL leads to a synergistic increase in cell death. We have previously demonstrated that TRAIL-deficient mice were less susceptible to paracetamol-induced liver damage, and that this partial protection clearly correlated with reduced hemorrhagic alterations. ${ }^{8}$ It is still a major unsolved question whether paracetamol induces cell death of LSEC directly or whether the observed LSEC damage and the resulting hemorrhagic alterations are primarily a consequence of the release of cytotoxic compounds from dying hepatocytes. Our in vitro experiments support the idea that LSECs represent a direct target of TRAIL and paracetamol; however, the possibility that toxic compounds released by hepatocytes may further contribute to the injury of the endothelial layer cannot be excluded.

These in vitro experiments reflect the observations made in vivo. In areas where paracetamol overdose was detrimental to hepatocytes, LSECs were equally absent (Figure 7). These observations suggest that both cell types, that is, hepatocytes as well as LSECs, are destroyed by an overdose of paracetamol.

Our results also confirmed a major cell death-regulating role of TRAIL in paracetamol-induced liver damage. The relevant source of endogenous TRAIL, though, is still uncertain. Liverhoming leukocytes including Kupffer cells, natural killer (NK) and natural killer T (NKT) cells have been shown to express TRAIL and to participate in the development of several forms of liver injury. ${ }^{21-23}$ Thus, we propose that liver-homing leukocytes within the sinusoids represent the source of TRAIL involved in the amplification of the cytotoxic effect of paracetamol on LSECs. This is in accordance to the report of Masson et al. ${ }^{24}$ who demonstrated a pathogenic role of NKT and NK cells in paracetamol-induced liver injury in mouse experiments, in which DMSO was used to dissolve paracetamol. They showed that DMSO was able to activate hepatic NKT and NK cells as indicated by increased NKT cell numbers and higher intracellular levels of cytotoxic effector molecules, such as IFN $\gamma$ and granzyme B. ${ }^{24}$ Moreover, it is well accepted that IFN $\gamma$ modulates the expression of TRAIL and TRAIL-Rs, ${ }^{25}$ suggesting that TRAIL expressed on activated NKT and NK cells could participate in paracetamol-induced liver damage.

Even though the hepatotoxic activity of paracetamol has been widely investigated, a conclusive picture on the mechanisms involved in paracetamol-induced liver 
a
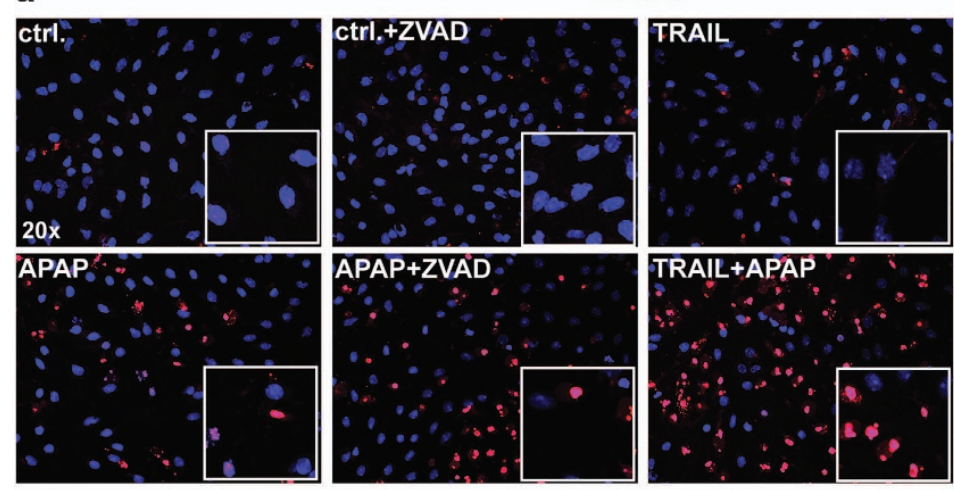

huLSEC
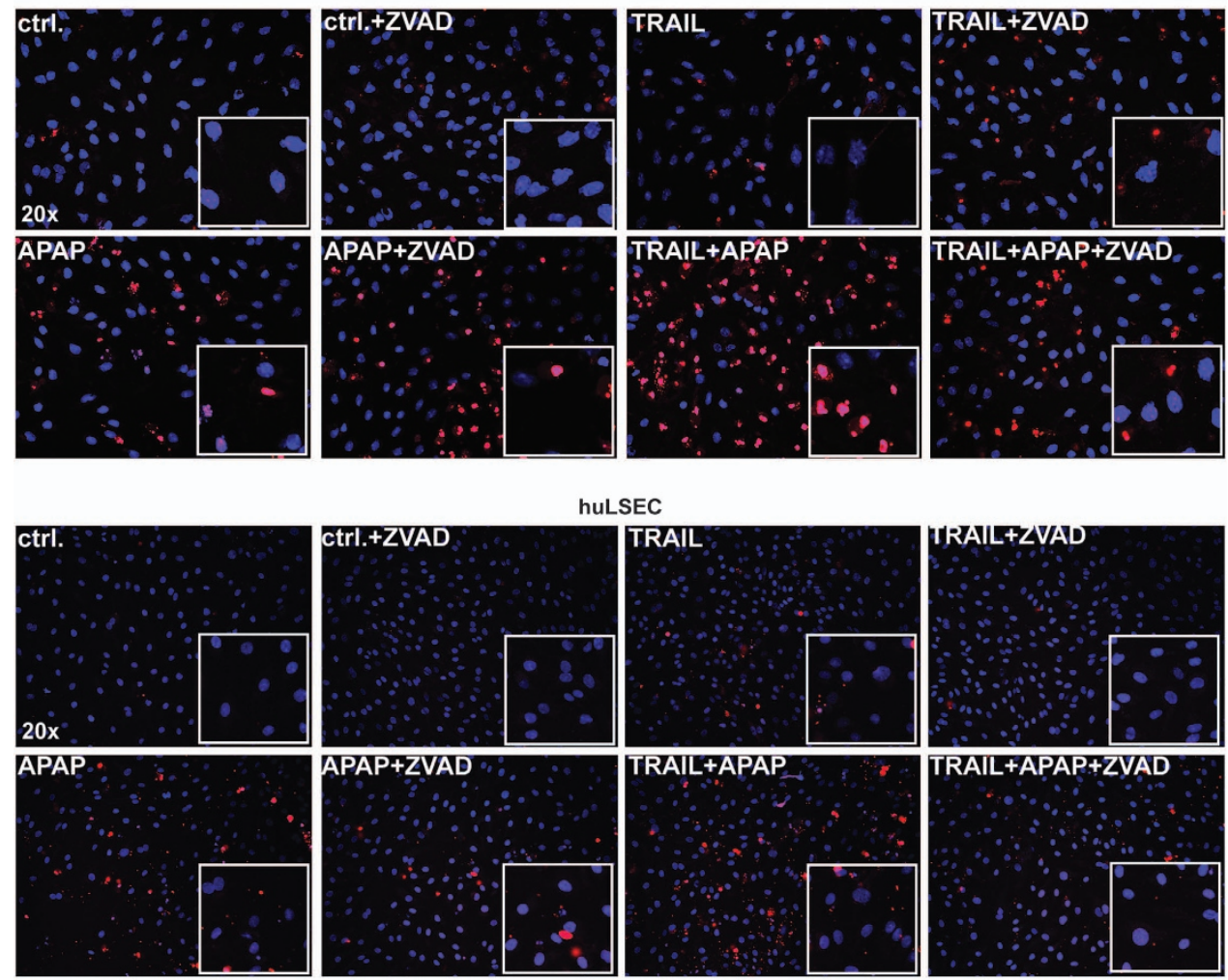

b
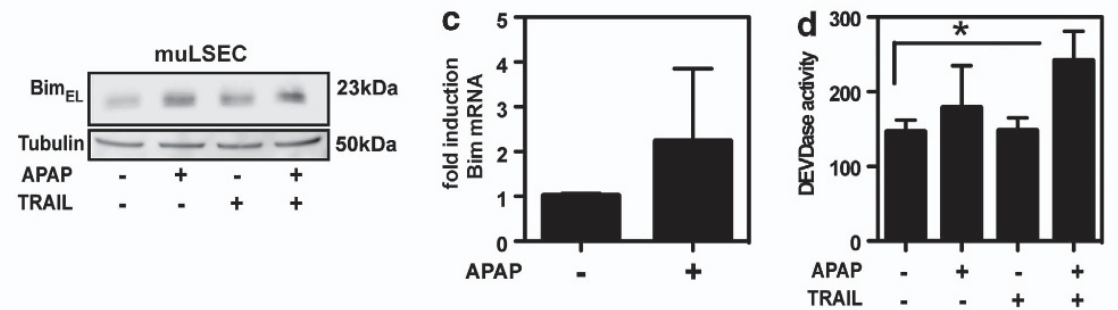

e
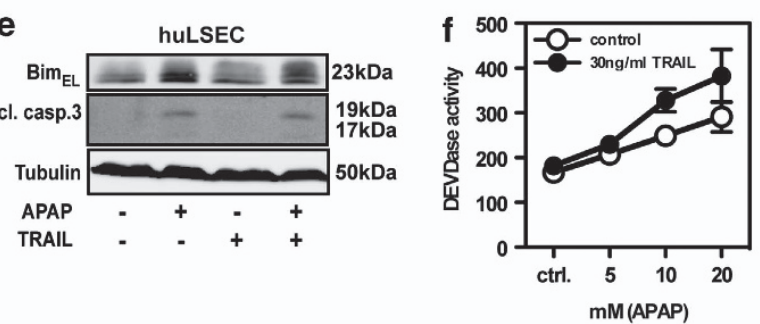

Figure 5 Paracetamol plus TRAIL induce cell death in primary murine as well as human LSECs in a Bim- and caspase-dependent manner. Murine and human LSECs were pretreated ( $30 \mathrm{~min}$ ) with Z-VAD-fmk and stimulated with $10 \mathrm{mM}$ paracetamol, $30 \mathrm{ng} / \mathrm{ml}$ TRAlL or the combination thereof for $16 \mathrm{~h}$, and visualized microscopically after Hoechst 33342 and PI staining. Inserts show a two-fold magnification from the center of the picture (a). Cells were treated with $10 \mathrm{mM}$ paracetamol and $30 \mathrm{ng} / \mathrm{ml}$ TRAIL, or the combination of both for $6 \mathrm{~h}$; and Bim, cleaved caspase 3 and Tubulin as loading control, were detected by western blot (b, e). Cells were stimulated for $6 \mathrm{~h}$ with $10 \mathrm{mM}$ paracetamol and bim-mRNA expression was measured by quantitative RT-PCR. GAPDH was used to normalize bim-expression levels (c). Murine and human LSECs were stimulated as described and DEVD cleavage was measured after $6 \mathrm{~h}(\mathbf{d}, \mathbf{f})$. Mean values \pm S.D. triplicates are shown for DEVDase assay. A typical experiment out of four is shown for microscopy analysis. Western blot for Bim was repeated two times, yielding similar results. Mean values \pm S.D. triplicates of independent pooled LSEC isolation are shown for RT-PCR

damage is still missing. One of the reasons is that the outcome of paracetamol-induced liver disease is most probably an interplay of several signaling events. Whereas paracetamol overdose seems to lead to a necrotic cell death in hepatocyte, we and others have demonstrated that mitochondrial events generally linked to apoptosis are also implicated. ${ }^{6,8}$ Our previous study identified JNK and Bim as critical players in paracetamol-induced hepatocyte.

With this current study we add new findings to the understanding of the mechanisms involved in paracetamol-induced 
WT
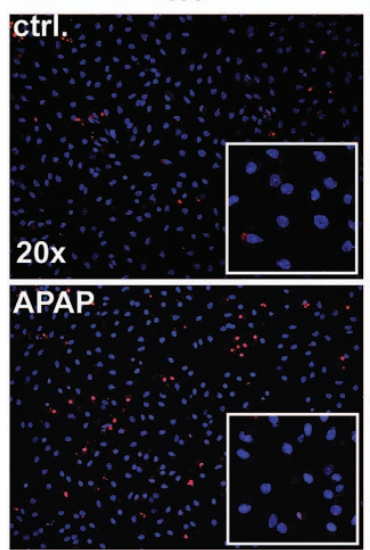

TRAIL

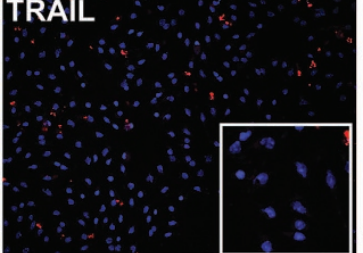

$\mathrm{A}+\mathrm{T}$

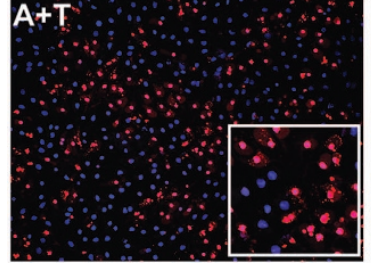

Bim-/-
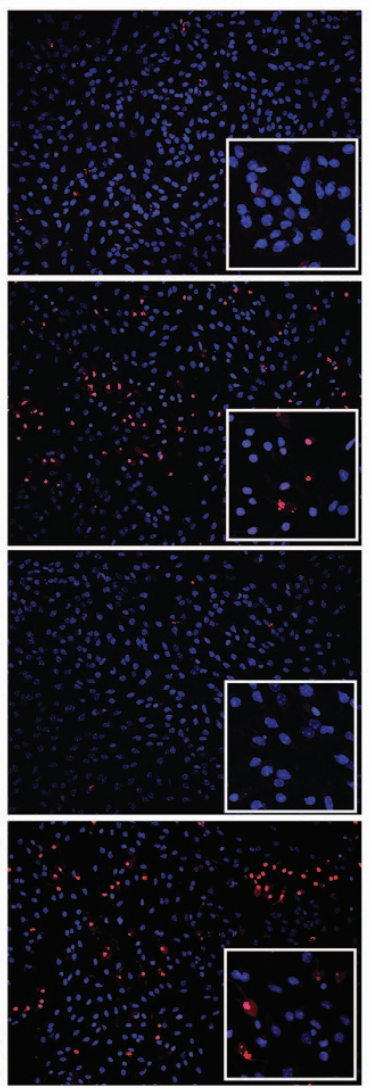

Bid-/-
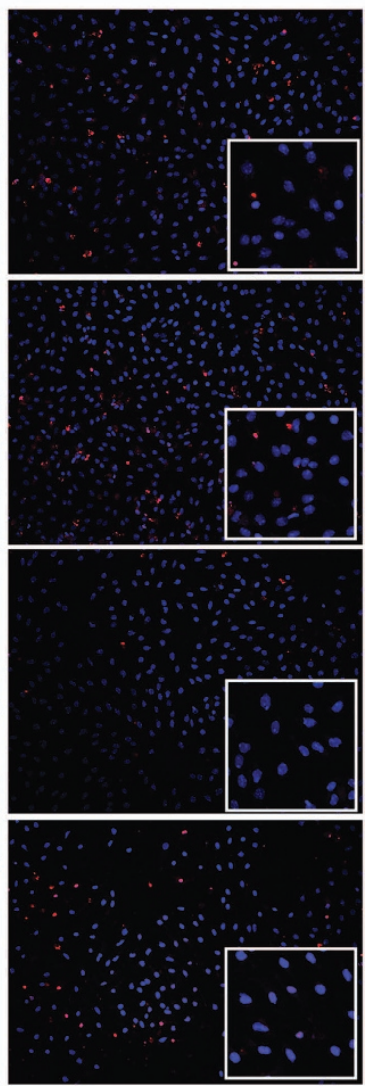

Figure 6 Bim- and Bid-deficient primary LSECs are protected from paracetamol plus TRAIL-induced cell death. Murine LSECs were isolated from wild-type (WT), Bim$\left(\mathrm{Bim}^{-/-}\right)$and Bid-deficient $\left(\mathrm{Bid}^{-/-}\right)$mice, were treated with $10 \mathrm{mM}$ paracetamol and $30 \mathrm{ng} / \mathrm{ml}$ TRAlL or the combination thereof for $16 \mathrm{~h}$ and cell death was visualized microscopically after Hoechst 33342 and PI staining. Inserts show a two-fold magnification from the center of the picture

ctrl.
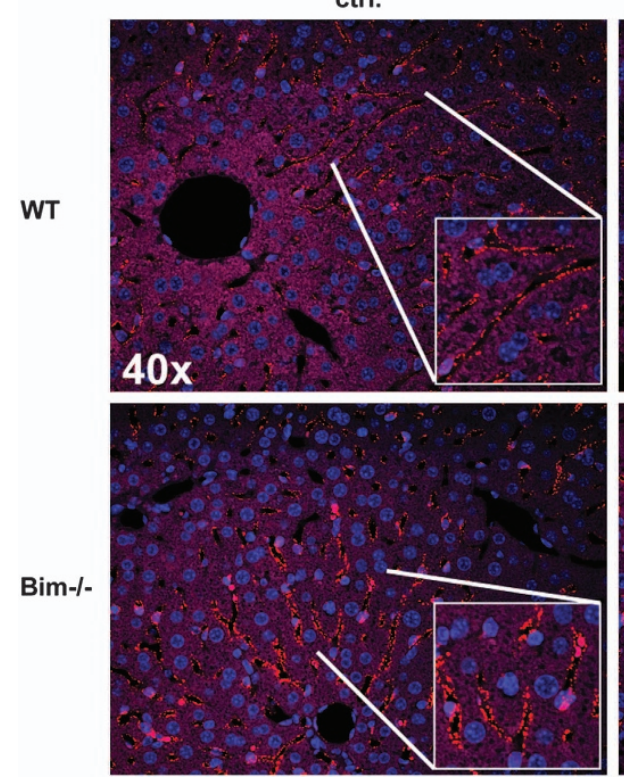

APAP
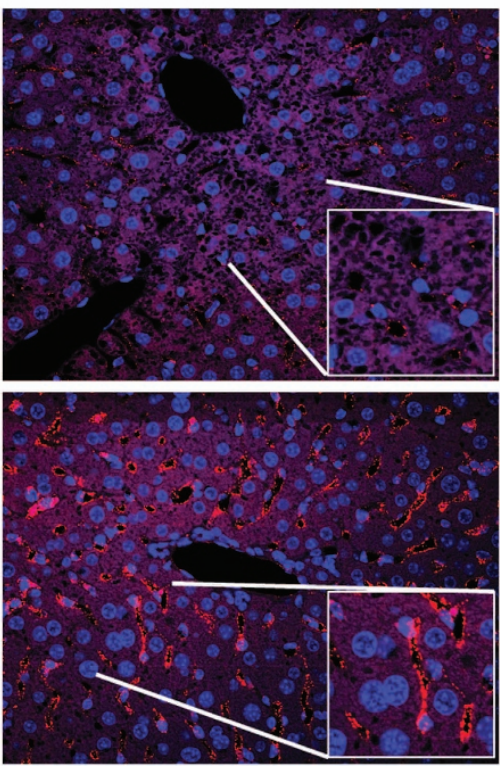

Figure 7 Bim ${ }^{-/-}$mice display more ovalbumin-Texas Red positive LSECs in paracetamol damaged liver sections. Wild type (WT) and Bim-deficient (Bim ${ }^{-/-}$) mice were injected with PBS as control or $400 \mathrm{mg} / \mathrm{kg}$ body weight paracetamol for $90 \mathrm{~min}$. Thirty minutes before the end of the experiment they were injected i.v. with $50 \mu \mathrm{g}$ ovalbumin-Texas Red. After perfusion fixation and paraffin embedding, liver sections were counterstained with DAPI, mounted in poly-Dabco and analyzed by fluorescence microscopy. A typical liver section out of six mice per group is shown 
liver damage. We demonstrate that similar mechanisms are operative in paracetamol-induced cell death in LSECs and hepatocytes. Paracetamol treatment of LSECs triggered the induction and activation of Bim, and downregulation of Bim resulted in a significant protection of LSECs from paracetamol plus TRAIL-induced cytotoxicity. In line with this proposed role of Bim in the control of LSEC death, the importance of Bim in endothelial cell death in the vasculature of solid tumors has recently been demonstrated. ${ }^{26}$

Similarly to hepatocytes, we identified JNK as a regulator of Bim transcription in LSECs. JNK has previously been associated with paracetamol-induced cell death. ${ }^{18,19}$ Henderson et al. ${ }^{18}$ demonstrated that paracetamol-induced hepatic JNK activation, and that JNK inhibition in vivo markedly reduced mortality of mice treated with paracetamol, with a significant reduction in hepatic necrosis and apoptosis. Similarly we demonstrated that activation of JNK downstream of paracetamol induces transcriptional expression of bim. ${ }^{8}$ The present study corroborates the existence of similar mechanisms in LSECs. Moreover, we demonstrate that Bid represents an important mediator in LSEC death. Although TRAIL does not seem to be required for the activation of Bim, TRAIL synergizes with paracetamol in activating Bid most likely via induction of caspase 8 activation and subsequent processing of Bid. It is still unclear why Bid cleavage is only detectable upon simultaneous treatment of cells with TRAIL and paracetamol but not upon treatment with a sub-lethal dose of TRAIL alone. An explanation could be that intracellular events activated by the administration of paracetamol leads to an increased susceptibility to TRAIL-induced activation of the mitochondrial apoptosis pathway. Sung et al. ${ }^{27}$ demonstrated that activation of the CHOP pathway sensitizes colon cancer cells to TRAIL-induced apoptosis. Moreover, it was also demonstrated that paracetamol induced endoplasmic reticulum (ER) stress. Nagy et al. ${ }^{28}$ showed that intraluminal redox imbalance of the ER and subsequent activation of pro-apoptotic events are involved in hepatocellular damage caused by paracetamol overdose. Beside this, Martín-Pérez et al. $^{29}$ recently demonstrated that ER stress sensitizes cells to TRAIL-induced cell death through downregulation of c-FLIP and upregulation of TRAIL-R2. To test whether downregulation of c-FLIP or upregulation of TRAIL$\mathrm{R} 2$ could be involved in the increased sensitivity of LSECs to TRAIL-induced apoptosis upon paracetamol treatment, we analyzed the expression of c-FLIP and TRAIL-R1 and R2. Although TRAIL-R1 and R2 were minimally affected by the treatment at the mRNA level (data not shown), we did observed a reduction of c-FLIP expression (Supplementary Figure 3). However, this could possibly also reflect the caspase-mediated cleavage and consumption of cFLIP after combined treatment of cells with TRAIL plus paracetamol. In line with this notion we demonstrated that a pan-caspase inhibitor was effective in attenuating murine as well as human LSEC death.

In summary, we demonstrated that LSECs represent a direct target of TRAIL and paracetamol-induced cytotoxicity, and that the resulting damage of the endothelial layer may represent an early event during paracetamolinduced liver damage contributing to the progression of the disease.

\section{Materials and Methods}

Cell lines. Human endothelial cell line skHep-1 (ATCC: HTB-52) (kindly provided by $\mathrm{C}$ Hammer, Division of Pathology, University of Bern, Switzerland) were cultured in DMEM containing 10\% FCS, 1\% HEPES (Sigma-Aldrich GmbH, Buchs, Switzerland), 1\% L-alanyl-L-glutamine (Biochrom AG, Berlin, Germany), $0.1 \%$ gentamycin (Sigma-Aldrich GmbH, Buchs, Switzerland) and $10 \mathrm{mM}$ hydrochloric acid (Merck KGaA, Darmstadt, Germany). Human umbilical vain endothelial cell line EA.hy926 (ATCC: CRL-2922) (kindly provided by Professor A Huwiler, Institute of Pharmacology, University of Bern, Bern, Switzerland) were cultured in RPMI-1640 containing 10\% FCS, $1 \%$ L-alanyl-L-glutamine and $0.1 \%$ gentamycin.

Mice and in vivo experiments. $\mathrm{Bim}^{-1-}$ and $\mathrm{Bid}^{-1-}$ mice (on the C57BL/6 background) were kindly provided by A Strasser (Walter and Eliza Hall Institute, Melbourne, Australia). Wild-type C57BL/6 mice were purchased from Harlan (Füllingdorf, Switzerland). All mice were bred and kept in individually ventilated cages in the Central Animal Facility of the Department of Medicine, University of Bern. Animal experiments were approved by the animal experimentation committee of the State of Bern. After $\mathrm{O} / \mathrm{N}$ fasting, mice were injected i.p. with $400 \mu \mathrm{l}$ PBS or APAP ( $400 \mathrm{mg} / \mathrm{kg}$ body weight) dissolved in warm PBS. After $60 \mathrm{~min}$, the mice were injected i.v. with $50 \mu \mathrm{g}$ ovalbumin-Texas Red (Molecular Probes, Lucerne, Switzerland) dissolved in $200 \mu \mathrm{l}$ PBS, and sacrificed $30 \mathrm{~min}$ later. The livers were perfused with $3 \%$ paraformaldehyde through the portal vein. After fixation for $24 \mathrm{~h}$ the livers were embedded in paraffin. Sections of $5 \mu \mathrm{m}$ were cut for subsequent staining with DAPI and analyses by fluorescence microscopy.

Cell death assay (MTT). skHep-1 and EA.hy926 cell lines were grown in logarithmic phase, harvested and plated in 96-well flat bottom plates. After $24 \mathrm{~h}$, cells were treated with increasing concentrations of paracetamol (N-acetyl-4aminophenol, Sigma-Aldrich GmbH, Buchs, Switzerland) and recombinant human TRAIL (R\&D Systems, Schonenbuch/Basel, Switzerland) for $16 \mathrm{~h}$. Cell viability was then assessed by 3-(4,5-dimethylthiazol-2-yl)-2,5-diphenyltetrazolium bromide (MTT) assay (Sigma-Aldrich $\mathrm{GmbH}$, Buchs, Switzerland) and normalized to untreated cell controls.

AnnexinV/PI staining. After treatment, cell death was monitored by AnnexinV-FITC (eBioscience, San Diego, CA, USA) and PI staining. Briefly, cells were harvested, centrifuged and resuspended in $50 \mu \mathrm{l}$ AnnexinV binding buffer (10 mM Hepes, pH 7.4, $150 \mathrm{mM} \mathrm{NaCl}, 5 \mathrm{mM} \mathrm{MgCl}_{2}$ and $1.5 \mathrm{mM} \mathrm{CaCl}_{2}$ ) containing $3 \mu \mathrm{g} / \mathrm{ml}$ AnnexinV-FITC. The cells were stained for $10 \mathrm{~min}$, washed with AnnexinV binding buffer, resuspended in $200 \mu \mathrm{l}$ AnnexinV binding buffer containing $1 \mu \mathrm{g} / \mathrm{ml}$ $\mathrm{PI}$ and analyzed on a FACScan flow cytometer (Becton Dickinson, Heidelberg, Germany). The percentage of AnnexinV-FITC positive cells was calculated using the Flow Jo software 8.8.6 (FlowJo, Ashland, OR, USA).

Caspase $\mathbf{3} / 7$ activity assay (DEVDase assay). skHep-1 and EA.hy926 were grown in logarithmic phase, harvested and plated in 96-well flat bottom plates. After O/N adherence, cells were stimulated with 5, 10 or $20 \mathrm{mM}$ APAP and/ or 30 or $3 \mathrm{ng} / \mathrm{ml}$ TRAIL, and harvested after $6 \mathrm{~h}$. In some experiments cells were pretreated with the JNK inhibitor V (Calbiochem, Merck KGaA, Darmstadt, Germany). Cells were washed and lysed in $100 \mu$ PBS containing 1\% Triton X-100 (Sigma-Aldrich GmbH, Buchs, Switzerland). After overnight lysis at $-20^{\circ} \mathrm{C}$, cells were centrifuged for $10 \mathrm{~min}$ at $1500 \times g$ at $4^{\circ} \mathrm{C}$, supernatant was harvested and $50 \mu \mathrm{l}$ were mixed with $50 \mu \mathrm{l}$ HEPES Buffer (100 mM HEPES, pH 7.5, 20\% glycerol, $0.5 \mathrm{mM}$ EDTA, $4 \mathrm{mMDTT}$ ) containing $100 \mathrm{mM}$ Ac-DEVD-AFC (Enzo Life Sciences AG, Lausen, Switzerland). Reactions were performed for $90 \mathrm{~min}$ at $37^{\circ} \mathrm{C}$, and enzymatic activity was measured on a spectrofluorometer ( $400 \mathrm{~nm}$ excitation, $505 \mathrm{~nm}$ emission). Background fluorescence was measured by incubating caspase substrate with lysis buffer.

Western blot analysis. skHep-1 and Ea.hy926 cell lines were treated as indicated, prior to lysis in cell lysis buffer containing $50 \mathrm{mM}$ Tris pH 6.8, 2\% SDS (Fluka Chemie GmbH, Buchs, Switzerland), $100 \mathrm{mMDTT}$ (Merck KGaA, Darmstadt, Germany), $10 \%$ glycerol and $0.1 \%$ bromphenolblue (Sigma-Aldrich $\mathrm{GmbH}$, Buchs, Switzerland). Cell lysates were separated by standard 15\% SDSPAGE and transferred to nitrocellulose membranes (Whatman GmbH, Dassel, Germany). Bim (1:1000, Sigma-Aldrich GmbH, Buchs, Switzerland), tBid $\left(1: 1000,{ }^{30}\right)$, cleaved caspase $3(1: 1000$, Cell Signaling Technology, Bioconcepts, 
Allschwil, Switzerland), cytochrome c (1:1000, BD Biosciences, Allschwil, Switzerland), porin (1:2000, Calbiochem, Merck, Zug, Switzerland) and FLIP (1:1000, Enzo life science, Lausen, Switzerland) were detected by incubation of membranes with the respective primary antibodies and corresponding horseradish peroxidase-labeled secondary antibodies. Signals were visualized by using the SuperSignal West Pico chemiluminescence reagents (Thermo Fisher Scientific Inc., Rockford, IL, USA) and detected on a Fujfilm LAS 4000 imaging system (Fujifilm Corporation, Akasaka, Japan). Equal protein loading was confirmed by detection of tubulin (1:5000, Sigma-Aldrich GmbH, Buchs, Switzerland).

Subcellular fractionation. One million skHep-1 and Ea.hy926 cells I were plated and stimulated as indicated. Cell were then harvested, centrifuged and their pellets were permeabilized for $5 \mathrm{~min}$ on ice with $200 \mu \mathrm{g} / \mathrm{ml}$ digitonin (Sigma-Aldrich $\mathrm{GmbH}$, Buchs, Switzerland) dissolved in $200 \mu$ l digitonin buffer (250 mM sucrose $70 \mathrm{mM} \mathrm{KCl}, 137 \mathrm{mM} \mathrm{NaCl}, 4.3 \mathrm{mM} \mathrm{Na}_{2} \mathrm{HPO}_{4}, 1.4 \mathrm{mM} \mathrm{KH}_{2} \mathrm{PO}_{4}, \mathrm{pH} 7.2$ ) and protease inhibitor cocktail tablets (Roche Diagnostics $\mathrm{GmbH}$, Mannheim, Germany). Cells were centrifuged for $5 \mathrm{~min}$ at $1000 \times g$ at $4{ }^{\circ} \mathrm{C}$ and cytosolic protein fraction was collected from the supernatant. The pellets were then solubilised in mitochondrial lysis buffer ( $50 \mathrm{mM}$ Tris, pH 7.4, $2 \mathrm{mM}$ EDTA, $0.3 \%$ Nonidet P-40, $150 \mathrm{mM} \mathrm{NaCl}, 2 \mathrm{mM}$ EGTA, $0.2 \%$ Triton X-100) followed by centrifugation for $10 \mathrm{~min}$ at $10000 \times g$ at $4{ }^{\circ} \mathrm{C}$. The mitochondrial protein fraction was collected from the supernatant. Cytosolic and mitochondrial fractions were analyzed for cytochrome $c$ and porin by western blotting.

Quantitative RT-PCR. Human and mouse bim-mRNA expression was detected by quantitative RT-PCR. Briefly, cells were lysed in TRI reagent (SigmaAldrich) and RNA was isolated. A total of $2 \mu \mathrm{g}$ of RNA were reverse transcribed using a high capacity kit (Applied Biosystems, Rotkreuz Zug, Switzerland). Quantitative RT-PCR was performed on the RT-PCR 7500 machine (Applied Biosystem, Rotkreuz Zug, Switzerland) using SYBR green and Quantitec primer assays (QIAGEN, Hilden, Germany). GAPDH was used to normalize bimexpression levels.

Downregulation of Bim and Bid by RNA interference. Cells were transfected with $10 \mathrm{nM}$ control, Bim- or Bid-specific siRNA (Dharmacon, Lafayette, CO, USA) and $12 \mu \mathrm{l}$ Hyperfect reagents (Qiagen AG, Hombrechtikon, Switzerland) in 6-cm-culture dishes for $24 \mathrm{~h}$. Cells were harvested and replated into 24-well or 96-well plates. After additional O/N culture, cells were stimulated as indicated for $1 \mathrm{~h}$ or $16 \mathrm{~h}$, respectively. Cells were either harvested for cell death assessment by AnnexinV-FITC/PI staining or for DEVDase assay analysis. Bim and Bid downregulation was controlled by western blot (Supplementary Figure 2).

Isolation of primary murine LSECs. Murine LSECs were isolated as described previously. ${ }^{31}$ In brief, mice were euthanized, the vena cava was cut and the liver lobes were perfused with $0.05 \%$ collagenase for $20 \mathrm{sec}$. Liver parenchymal cells were dissociated by shaking for maximum $20 \mathrm{~min}$ at 240 r.p.m. and subsequently passed through a $250 \mu \mathrm{m}$ filter. A Nycodens density gradient centrifugation (Axonlab, Baden, Switzerland) was applied to further separate LSECs. The cell suspension was labeled with anti-CD146 MicroBeads (Miltenyi Biothec GMBH, Bergisch Gladbach, Germany) and magnetic separation was performed on MACS columns. Isolated LSECs were cultured on collagencoated plates in DMEM (Sigma-Aldrich $\mathrm{GmbH}$, Buchs, Switzerland) with $10 \%$ FCS, $2 \%$ L-alanyl-L-glutamine and $0.1 \%$ gentamycin for 2 days. LSEC purity, generally more than $95 \%$, was confirmed by the incorporation of fluorescencelabeled acetylated low-density lipoprotein (data not shown), which results in a typical endosomal fluorescence pattern when observed under the fluorescence microscope. Cells were then rested for at least 1 day before they were used in experiments.

Isolation of primary human LSECs. Human liver endothelial cells were isolated from liver tissue from patients undergoing surgical liver resection. The tissue was collected with informed consent and under local ethics committee approval of the University of Bern. Approximately $30 \mathrm{~g}$ of liver was cut into $2 \mathrm{~mm}^{3}$ pieces and digested in $50 \mathrm{ml}$ PBS containing $10 \mathrm{mg} / \mathrm{ml}$ collagenase $1 \mathrm{~A}$ (SigmaAldrich $\mathrm{GmbH}$ ) for $90 \mathrm{~min}$ at $37^{\circ} \mathrm{C}$. The resultant solution was then filtered through a sterile $0.5 \mathrm{~mm}$ steel mesh, the supernatant centrifuged at $300 \times g$ for $8 \mathrm{~min}$, and the pellet then resuspended on $10 \mathrm{ml}$ PBS. This digest was then layered on a $33 \% / 77 \%$ Percoll density gradient, centrifuged for $30 \mathrm{~min}$ at $800 \times \mathrm{g} 4{ }^{\circ} \mathrm{C}$ and the non-parenchymal layer removed, pelleted and resuspended in $500 \mu \mathrm{l}$ of PBS.
Endothelial cells were isolated from this fraction by immunomagnetic selection using a mouse anti-CD31 antibody (Dako, Baar, Switzerland), followed by an antimouse IgG Dynabead, 30 min incubation with each and magnetic separation was performed on MACS columns. Isolated LSECs were cultured on collagen-coated plates. Human LSECs were cultured in SFM endothelial basal media (Gibco, Luzern, Switzerland) with $10 \%$ human serum, $0.1 \%$ gentamycin, $5 \mathrm{ng} / \mathrm{ml}$ hepatocyte growth factor (HGF, Peprotech, Luzern, Switzerland) and $10 \mathrm{ng} / \mathrm{ml}$ vascular endothelial growth factor (VEGF, Peprotech).

Fluorescence microscopy. Paraffin sections from paracetamol- and control-treated mice injected with ovalbumin-Texas red were deparaffinized and stained for 2 min with $600 \mathrm{nM}$ DAPI (Invitrogen, Lucerne, Switzerland), washed in TBS and embedded in poly-Dabco, prior to analysis by fluorescence microscopy (Olympus IX81 FluoView FV1000, Volketswil, Switzerland).

\section{Conflict of Interest}

The authors declare no conflict of interest.

Acknowledgements. We thank S Freese for reagents, A Huwiler for providing the Ea.hy926 cells and P Knolle for the technical support in the isolation of murine LSECs. This study was supported by a grant from the Novartis Foundation (No.11B62) to NC.

1. Rumack BH. Acetaminophen misconceptions. Hepatology 2004; 40: 10-15.

2. Lee WM. Acetaminophen and the U.S. acute liver failure study group: lowering the risks of hepatic failure. Hepatology 2004; 40: 6-9.

3. Burcham PC, Harman AW. Acetaminophen toxicity results in site-specific mitochondrial damage in isolated mouse hepatocytes. J Biol Chem 1991; 266: 5049-5054.

4. Masubuchi $Y$, Suda $C$, Horie T. Involvement of mitochondrial permeability transition in acetaminophen-induced liver injury in mice. J Hepatol 2005; 42: 110-116.

5. Cover C, Mansouri A, Knight TR, Bajt ML, Lemasters JJ, Pessayre D et al. Peroxynitriteinduced mitochondrial and endonuclease-mediated nuclear DNA damage in acetaminophen hepatotoxicity. J Pharmacol Exp Ther 2005; 315: 879-887.

6. Bajt ML, Farhood A, Lemasters JJ, Jaeschke H. Mitochondrial bax translocation accelerates DNA fragmentation and cell necrosis in a murine model of acetaminophen hepatotoxicity. J Pharmacol Exp Ther 2008; 324: 8-14.

7. El-Hassan H, Anwar K, Macanas-Pirard P, Crabtree M, Chow SC, Johnson VL et al. Involvement of mitochondria in acetaminophen-induced apoptosis and hepatic injury: roles of cytochrome c, Bax, Bid, and caspases. Toxicol Appl Pharmacol 2003; 191: 118-129.

8. Badmann A, Keough A, Kaufmann T, Bouillet P, Brunner T, Corazza N. Role of TRAIL and the pro-apoptotic Bcl-2 homolog Bim in acetaminophen-induced liver damage. Cell Death Dis 2011; 2: e171.

9. Ito $\mathrm{Y}$, Bethea NW, Abril ER, McCuskey RS. Early hepatic microvascular injury in response to acetaminophen toxicity. Microcirculation 2003; 10: 391-400.

10. Lim SP, Andrews FJ, O'Brien PE. Acetaminophen-induced microvascular injury in the rat liver: protection with misoprostol. Hepatology 1995; 22: 1776-1781.

11. McCuskey RS, Bethea NW, Wong J, McCuskey MK, Abril ER, Wang X et al. Ethanol binging exacerbates sinusoidal endothelial and parenchymal injury elicited by acetaminophen. J Hepatol 2005; 42: 371-377.

12. Walker RM, Racz WJ, McElligott TF. Scanning electron microscopic examination of acetaminophen-induced hepatotoxicity and congestion in mice. Am J Pathol 1983; 113: 321-330.

13. DeLeve LD, Wang X, Kaplowitz N, Shulman HM, Bart JA, van der Hoek A. Sinusoidal endothelial cells as a target for acetaminophen toxicity. Direct action versus requirement for hepatocyte activation in different mouse strains. Biochem Pharmacol 1997; 53: $1339-1345$.

14. Edgell CJ, McDonald CC, Graham JB. Permanent cell line expressing human factor VIII-related antigen established by hybridization. Proc Natl Acad Sci USA 1983; 80: 3734-3737.

15. DeLeve LD, Wang X, Kuhlenkamp JF, Kaplowitz N. Toxicity of azathioprine and monocrotaline in murine sinusoidal endothelial cells and hepatocytes: the role of glutathione and relevance to hepatic venoocclusive disease. Hepatology 1996; 23: 589-599.

16. Steinberg P, Lafranconi WM, Wolf CR, Waxman DJ, Oesch F, Friedberg T. Xenobiotic metabolizing enzymes are not restricted to parenchymal cells in rat liver. Mol Pharmacol 1987; 32: 463-470.

17. Steinberg P, Schlemper B, Molitor E, Platt KL, Seidel A, Oesch F. Rat liver endothelial and Kupffer cell-mediated mutagenicity of polycyclic aromatic hydrocarbons and aflatoxin B1. Environ Health Perspect 1990; 88: 71-76.

18. Henderson NC, Pollock KJ, Frew J, Mackinnon AC, Flavell RA, Davis RJ et al. Critical role of c-jun (NH2) terminal kinase in paracetamol- induced acute liver failure. Gut 2007; 56: 982-990. 
19. Gunawan BK, Liu ZX, Han D, Hanawa N, Gaarde WA, Kaplowitz N. c-Jun N-terminal kinase plays a major role in murine acetaminophen hepatotoxicity. Gastroenterology 2006; 131: 165-178

20. Wang L, Zhao D, Suehiro T, Boros P, Miller CM. Assessment of damage and recovery of sinusoidal endothelial cell function by in vivo hyaluronic acid uptake in cold-preserved and transplanted rat livers. Transplantation 1996; 62: 1217-1221.

21. Beraza N, Malato Y, Sander LE, Al-Masaoudi M, Freimuth J, Riethmacher D et al. Hepatocyte-specific NEMO deletion promotes NK/NKT cell- and TRAIL-dependent liver damage. J Exp Med 2009; 206: 1727-1737.

22. Kahraman A, Barreyro FJ, Bronk SF, Werneburg NW, Mott JL, Akazawa Y et al. TRAIL mediates liver injury by the innate immune system in the bile duct-ligated mouse. Hepatology 2008; 47: 1317-1330.

23. Takeda K, Hayakawa Y, Smyth MJ, Kayagaki N, Yamaguchi N, Kakuta S et al. Involvement of tumor necrosis factor-related apoptosis-inducing ligand in surveillance of tumo metastasis by liver natural killer cells. Nat Med 2001; 7: 94-100.

24. Masson MJ, Carpenter LD, Graf ML, Pohl LR. Pathogenic role of natural killer T and natural killer cells in acetaminophen-induced liver injury in mice is dependent on the presence of dimethyl sulfoxide. Hepatology 2008; 48: 889-897.

25. Sedger LM, Shows DM, Blanton RA, Peschon JJ, Goodwin RG, Cosman D et al. IFNgamma mediates a novel antiviral activity through dynamic modulation of TRAIL and TRAIL receptor expression. J Immunol 1999; 163: 920-926.

26. Naik E, O'Reilly LA, Asselin-Labat ML, Merino D, Lin A, Cook M et al. Destruction of tumo vasculature and abated tumor growth upon VEGF blockade is driven by proapoptotic protein Bim in endothelial cells. J Exp Med 2011; 208: 1351-1358.
27. Sung B, Ravindran J, Prasad S, Pandey MK, Aggarwal BB. Gossypol induces death receptor- 5 through activation of the ROS-ERK-CHOP pathway and sensitizes colon cancer cells to TRAIL. J Biol Chem 2010; 285: 35418-35427.

28. Nagy G, Kardon T, Wunderlich L, Szarka A, Kiss A, Schaff $Z$ et al. Acetaminophen induces ER dependent signaling in mouse liver. Arch Biochem Biophys 2007; 459: 273-279.

29. Martin-Perez R, Niwa M, Lopez-Rivas AER. ER stress sensitizes cells to TRAIL through down-regulation of FLIP and Mcl-1 and PERK-dependent up-regulation of TRAIL-R2. Apoptosis 2012; 17: 349-363.

30. Kaufmann T, Tai L, Ekert PG, Huang DC, Norris F, Lindemann RK et al. The BH3-only protein bid is dispensable for DNA damage- and replicative stress-induced apoptosis or cell-cycle arrest. Cell 2007; 129: 423-433.

31. Diehl L, Schurich A, Grochtmann R, Hegenbarth S, Chen L, Knolle PA. Tolerogenic maturation of liver sinusoidal endothelial cells promotes B7-homolog 1-dependent CD8 + T cell tolerance. Hepatology 2008; 47: 296-305.

Cell Death and Disease is an open-access journal published by Nature Publishing Group. This work is licensed under the Creative Commons Attribution-NonCommercial-No Derivative Works 3.0 Unported License. To view a copy of this license, visit http://creativecommons.org/licenses/by-nc-nd/3.0/

Supplementary Information accompanies the paper on Cell Death and Disease website (http://www.nature.com/cddis) 